\title{
Innovative Technologies In The Assessment Of Accumulation And Erosion Processes In The Channels
}

\author{
Aybek Arifjanov' ${ }^{1}$ Luqmon Samiyev ${ }^{2}$, Islombek Akhmedov ${ }^{3}$, \\ Dinislam Atakulov ${ }^{4}$
}

${ }^{1}$ DSc, professor, Head of the department of Hydraulics and Hydroinformatics, Faculty of Hydromelioration, Tashkent Institute of Irrigation and Agricultural Mechanization Engineers, Tashkent, Uzbekistan,

E-mail: www.obi-life@mail.ru

${ }^{2} \mathrm{PhD}$, Department of Hydraulics and Hydroinformatics, Faculty of Hydromelioration, Tashkent Institute of Irrigation and Agricultural Mechanization Engineers, Tashkent, Uzbekistan.

E-mail: gidravlika-obi-life.zn.uz

${ }^{3} \mathrm{PhD}$, Department of technology of production of building materials products and structures, Faculty of construction technology, Namangan engineering construction institute, Namangan, Uzbekistan.

E-mail: islombek.ahmedov@bk.ru

${ }^{4}$ Assistant, Department of Hydraulics and Hydroinformatics, Faculty of Hydromelioration, Tashkent Institute of Irrigation and Agricultural Mechanization Engineers, Tashkent, Uzbekistan.

E-mail: irrigator-atakulov@mail.ru

Article History: Received:11 January 2021; Accepted: 27 February 2021; Published online: 5 April 2021

Abstract: The article discusses the possibilities of assessing the state of river beds and changes in them using remote sensing technologies (RS) and geographic information systems (GIS). With the help of geoinformation technologies, an assessment of deformation phenomena over the past 25 years in the channel of the Sokh river, which was chosen as the object of research, was given. Channel phenomena have been studied using data obtained from satellites. To analyze the situation, a model of the Landsat satellite was selected. The currently widely used official Glo Vis website was used to download the data. Data analyzed using ArcMap software. The results of the GIS data analysis were compared with the data of field studies. Over the past 20 years, along the channel, changes have been observed on the right bank, filling a part of the left bank with sediment particles, germination of moisture-loving plants and the process of erosion of the left bank. Over the past 5 years, about 30 meters of irrigated areas have eroded along the right bank between pickets PK3 and PK4. These changes average 5-6 meters per year. An analysis of the deformation processes occurring in the Sokh channel is carried out and conclusions are drawn.

Keywords: GIS, Landsat, satellite, river, map, channels, flow, water consumption, image analysis, morphometry.

\section{Introduction}

Impacts on the environment and processes related to climate change are also reflected in river basins. It is known from the analysis of the available literature and data on the processes in the riverbed that today the solution of these problems is carried out on the basis of many natural field studies [1,2]. Because the practical application of theoretical developments in this area requires rapid initial data. MOO and GAT technologies are among the most advanced methods in developed countries for fast and continuous data acquisition. Prompt response to emergencies and timely action are key issues. In the design of hydraulic structures built on the river, there is a need for scientific research aimed at improving the methods of hydraulic calculations, taking into account the changing factors in the river. One of the important tasks is the implementation of this task, including monitoring of the technical condition of irrigation systems and hydraulic structures, scientific research on improving the methods of remote accounting of water consumption based on resource-saving techniques, technologies $[3,4,5]$.

\section{Literature review and problem statement}

Today, the models created using GAT technologies in the Republic mainly provide the location of water resources and linear schemes of their mapping, do not create a database to determine the status of water resources, the mode of operation of hydraulic structures and accumulative and erosion processes in the river $[6,7,8]$. The main problem in the use of GAT models in the management and use of water resources is their low accuracy, the fact that the models are based on low-resolution satellite images, the use of old methods of analysis. In this regard, the study of changes in the riverbed and the technical condition of hydraulic structures using the technology of remote sensing (MOO) and geographic information systems (GAT) in irrigation systems is of particular importance [9,10,11]. Currently, more than 300 satellites are operating in space to solve the problems of economic sectors. They are all designed for a specific stage, and after launch into space, the possibilities are being tested in other areas as well [12,13,14]. Well-coordinated, geographically linked Landsat satellite imagery was used to study the state of accumulative and erosion processes in the riverbed. Landsat satellites are the first satellite system to appear in this space [15,16]. Landsat satellites have the ability to 
transmit data since 1972. However, the first Landsat 1-3 satellites are now sending poor-quality images to Earth due to the ingress of space dust into the scanner optics $[17,18,19]$. In this study, data from Landsat 4-8 satellites were used. Initially, data from the Soxsay River for the period 1995-2020 were downloaded from https:// earthexplorer.usgs.gov/. The data were analyzed using ArcMap software (Figure 1).

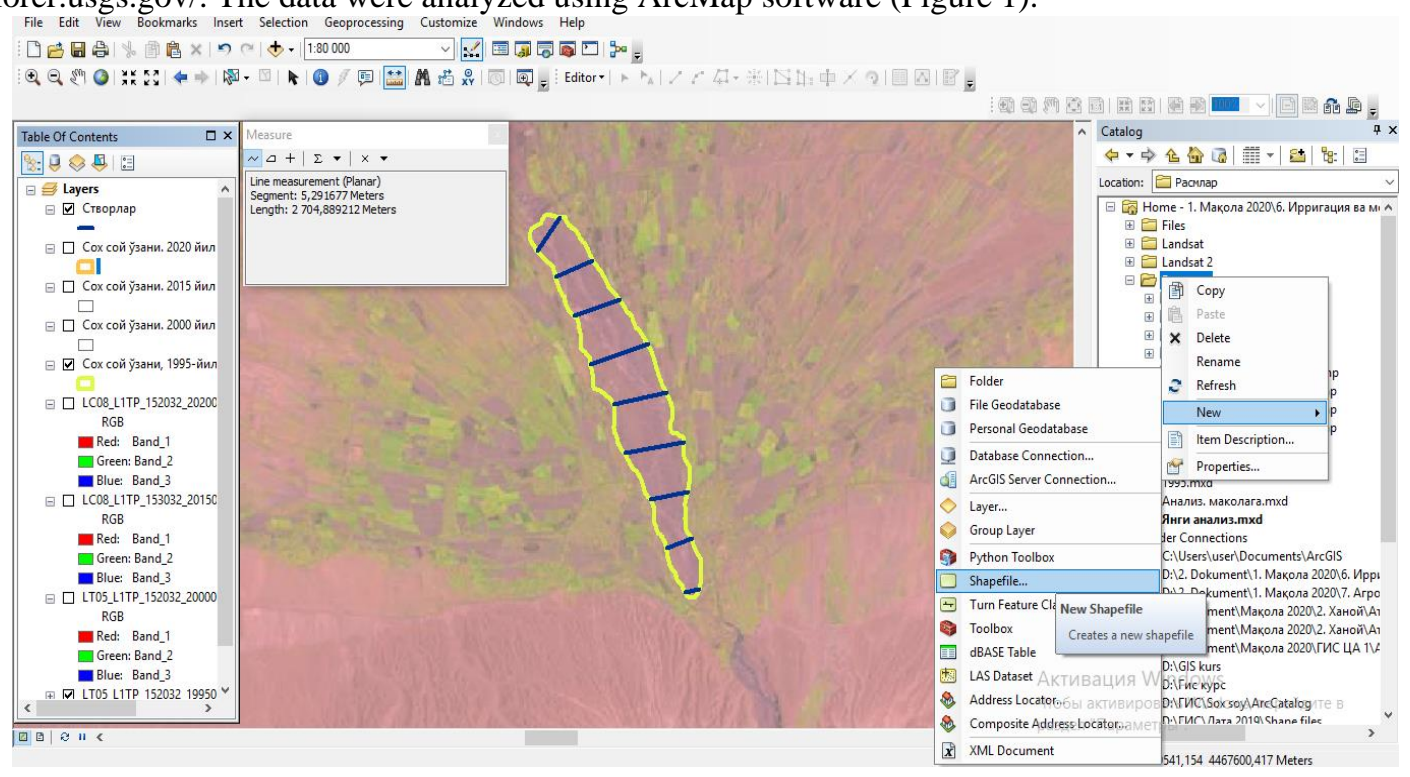

Figure 1. Perform steps on data in ArcMap

Parameters of the Sokhsay river, which receives water from the Sarikurgan hydroelectric power station: the total length of the river is $9.4 \mathrm{~km}$, the average width is $550 \mathrm{~m}$, the average depth is $1.1 \mathrm{~m}$, the average slope is $\mathrm{i}=0.01$. The maximum water consumption is up to $180 \mathrm{~m} 3$ and varies over the years. A distinctive feature of the Cox River is that the water flows in a certain part of the year. In the spring, water begins to flow into the riverbed in late May, and in some cases, water flows into the riverbed in early June and stops flowing into the riverbed in mid-September $[20,21,22]$. This movement of the flow makes it possible to increase the accuracy of the hydraulic measurements and the data obtained to a certain extent.

Outcome analysis and examples

In order to study the processes in the valley, 9 places along the length of the stream were selected. Changes in channel width and surface area have been observed in each place over the years (Table 1.2). According to the results of the last 25 years in the Sox River, the river has also changed its shape (Figures 2 and 3).

Table 1

Sox river surface area changes over the years

\begin{tabular}{|c|c|c|}
\hline № & Observed years & $\begin{array}{c}\text { Surface square of Sokhsay } \\
\text { river (hectare) }\end{array}$ \\
\hline 1 & 1995 & 748 \\
\hline 2 & 2000 & 602 \\
\hline 3 & 2015 & 511 \\
\hline 4 & 2020 & 507 \\
\hline
\end{tabular}

Table 2

Change in river width over years

\begin{tabular}{|c|c|c|c|c|}
\hline \multirow{2}{*}{$\begin{array}{c}\text { Number of } \\
\text { selected } \\
\text { places }\end{array}$} & \multicolumn{4}{|c|}{ width, (m) over the years } \\
\cline { 2 - 5 } & 1995 & 2000 & 2015 & 2020 \\
\hline 1 & 244 & 213 & 102 & 209 \\
\hline 2 & 556 & 422 & 422 & 422 \\
\hline 3 & 791 & 823 & 495 & 495 \\
\hline 4 & 1251 & 956 & 729 & 697 \\
\hline 5 & 1119 & 779 & 446 & 506 \\
\hline 6 & 1270 & 781 & 781 & 699 \\
\hline
\end{tabular}


Innovative Technologies In The Assessment Of Accumulation And Erosion Processes In The Channels

\begin{tabular}{|c|c|c|c|c|}
7 & 1007 & 799 & 1022 & 1022 \\
\hline 8 & 844 & 844 & 670 & 839 \\
\hline 9 & 806 & 806 & 712 & 712 \\
\hline
\end{tabular}
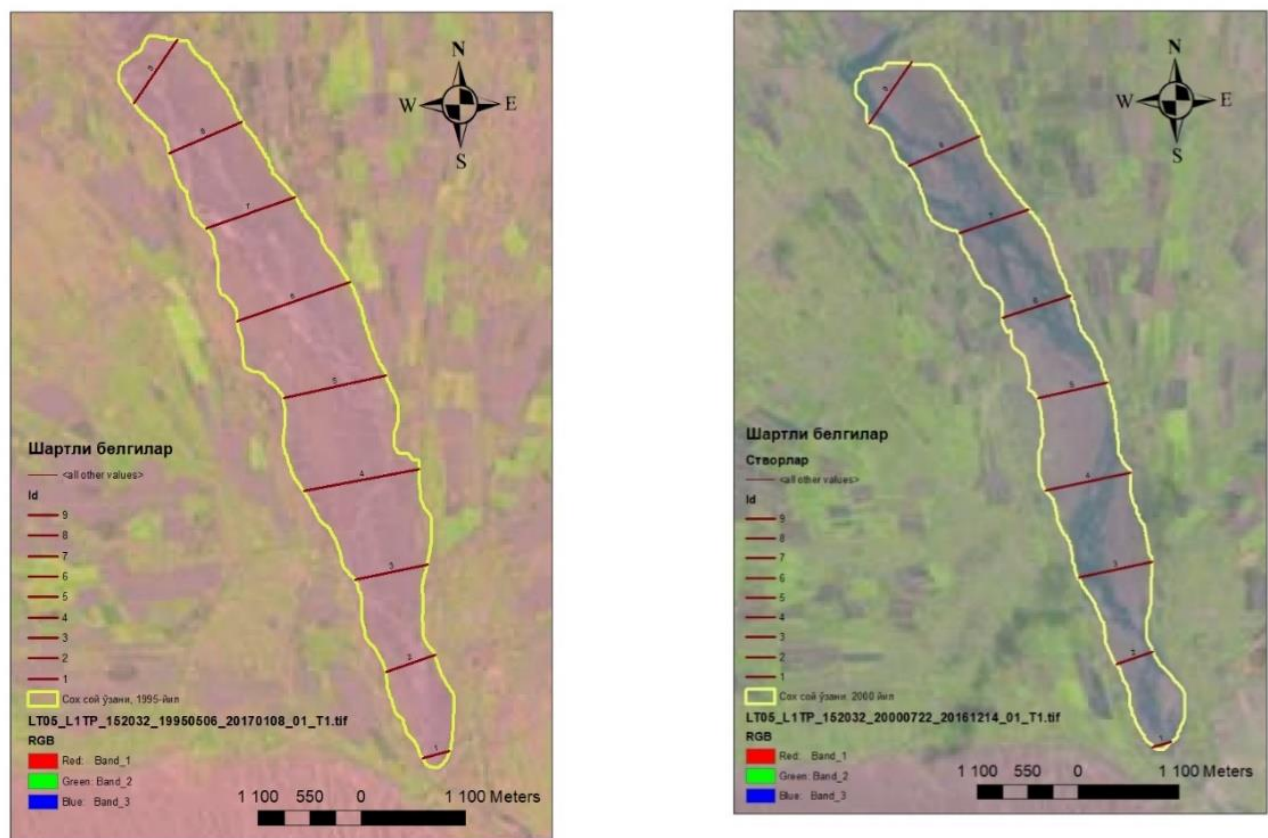

Figure 2. The state of the Sohk River in 1995 Figure 3. The state of the Sokh River in 2000

It can be observed that the width of the stream changed at almost every picket. At the same time, it can be seen that the width of the middle part of the riverbed has narrowed, and grasses and trees have grown in the sandygravel areas for 5 years. The main reason for this is that the flow changes its direction many times during the year and the amount of sediment moving in the flow structure is large. A similar situation can be observed in the last 5 years (Fig. 4.5).

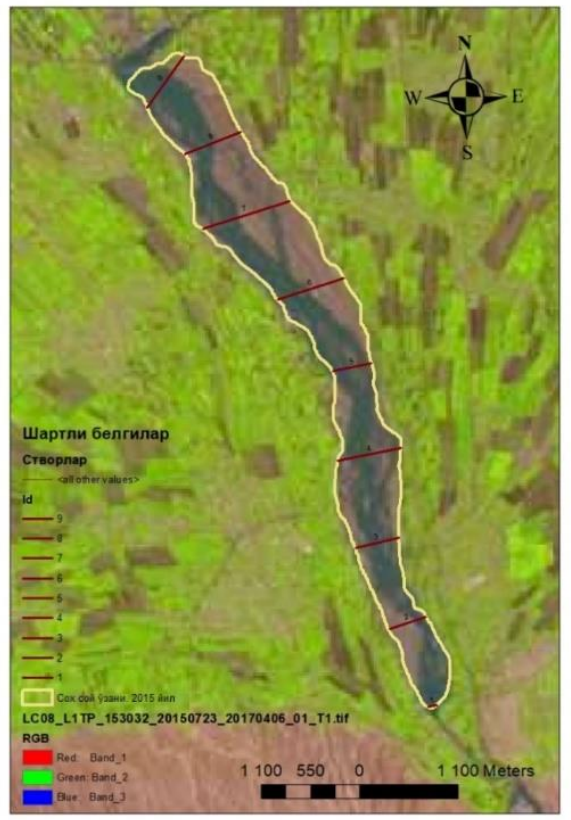

Figure 4. The state of the Sokh River in 2015

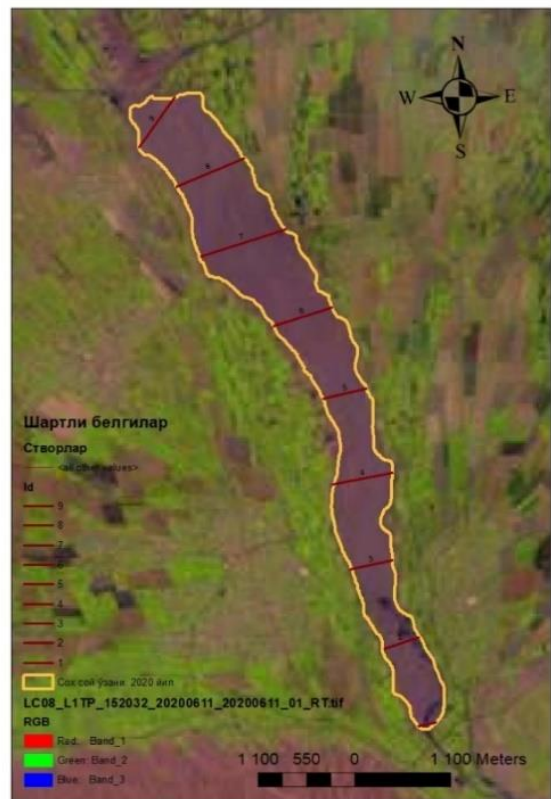

Figure 5. The state of the Sokh River in 2020

It can be seen that the river has been washed along the right bank for the last 5 years. At the beginning of the 2nd stanza of the stream it can be seen that the stream is moving mainly on the right bank, and at the end of the 
9th place, on the contrary, on the left bank. In order to study and investigate the deformation processes occurring in the riverbed, field research was conducted in the riverbed Sox. The data obtained as a result of the measurement work were analyzed. When the sox riverbed was inspected, it was observed that the initial part of the soybean was washed away (Fig. 6). The main reason for this is that the stream has changed its direction along the right bank. Over the last 20 years, there has been a change in the direction of the flow along the right bank, the river is filled with turbid particles on the left bank, grass growth and washing processes on the right bank.
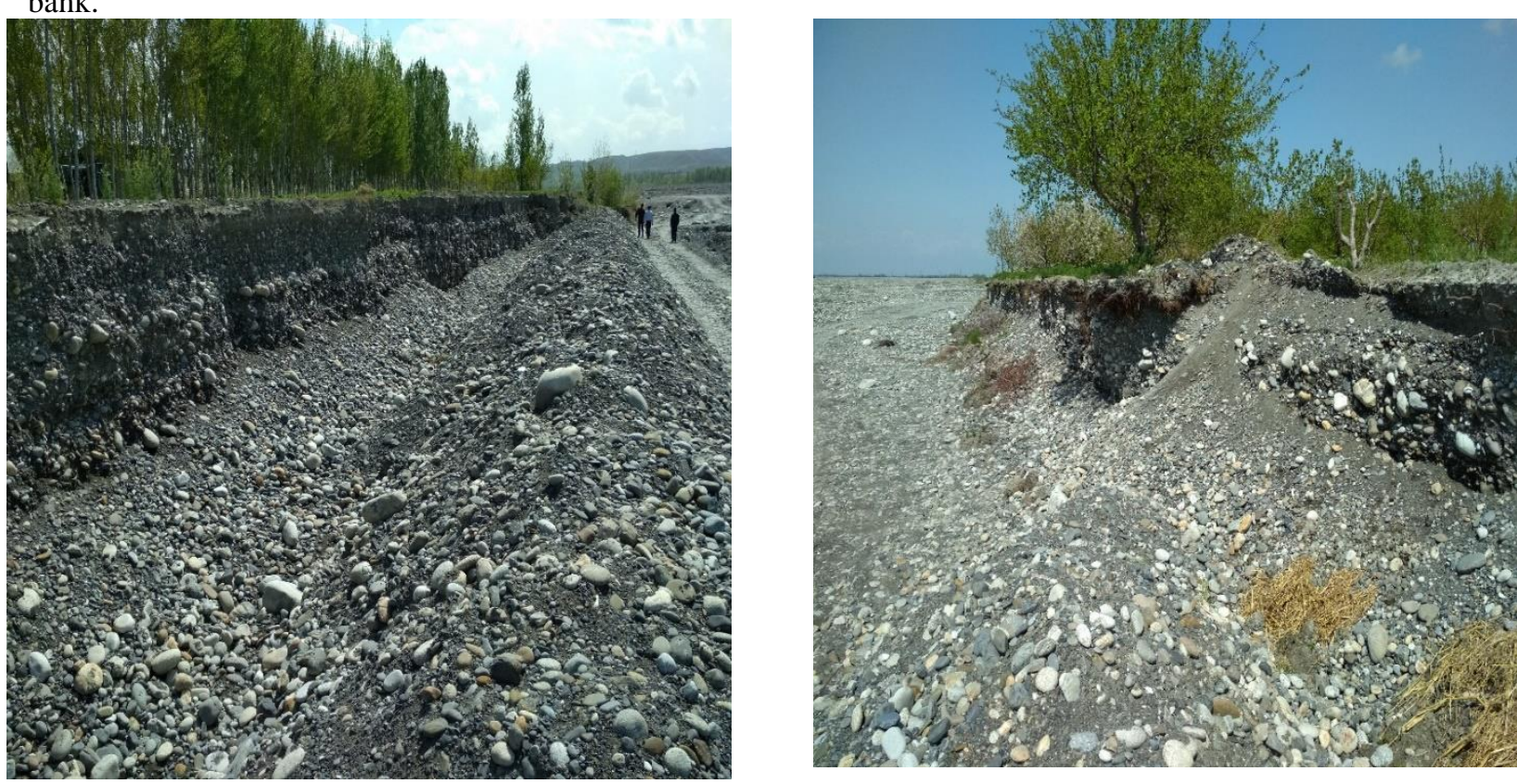

Figure 6. 35 picket of Sokh River, right bank

During the last 5 years, it was observed that $30 \mathrm{~m}$ washed to the right bank in the range of $3-4$ selected places. These changes average 5-6 meters each year. This is leading to the destruction of orchards and crops on the right bank.

Discussion and conclusion

The study of problematic, accumulative and erosion processes in the river basin was based on the possibility of organizing on the basis of Earth satellites, thereby reducing the consumption of excess resources, increasing the accuracy of results, creating various models, databases, their application in agriculture and water management. The possibilities of geoinformation technologies in the assessment of erosion and accumulation processes in the valley were analyzed. In the study, GPS points were taken from 9 sections to study the deformation of the valley in certain sections of the Sokh River, and the geodetic position of these points was measured. These data provide the basis for future mapping of the river deformation, blurred printing, and washing model. It was seen as a solution to both economic and environmental problems. The implementation of the program based on GAT techniques and technologies will be a new direction for the rapid and accurate assessment of deformation processes in the riverbed, effective monitoring of water consumption. Based on the created maps, a database was formed and recommended for future work. As a result of research, time and resource savings have been achieved.

\section{References}

1. Arifjanov, A.M. Distribution of Suspended Sediment Particles in a Steady-State Flow. Water Resources. Volume 28, Issue 2, 2001, Pages 164-166. DOI: 10.1023/A:1010375500148

2. Arifjanov, A.M. Method for calculation of the distribution of drift particles in variable section beds (VSB). Gidrotekhnicheskoe Stroitel'stvo. Issue 2, 2004, Pages 44-45. ISSN: 00169714

3. Aybek Arifjanov, Luqmon Samiev, Shamshodbek Akmalov Dependence of Fractional Structure of River Sediments on Chemical Composition. International Journal of Innovative Technology and Exploring Engineering (IJITEE) ISSN: 2278-3075, Volume-9 Issue-1, Pp. 2646-2648. November 2019

4. Arifjanov A.M., Fatxullaev A.M. Natural Studies for Forming Stable Channel Sections. Volume 1425, Issue 1, 8 January 2020, Номер статьи 012025. International Scientific Conference on Modelling and Methods of Structural Analysis 2019, MMSA 2019; Moscow; Russian Federation; 13 November 2019 до 15 November 2019; Код 156713. DOI: 10.1088/1742-6596/1425/1/012025

5. Arifjanov, A., Dalabaev, U., Abduraimova, D., Babaev, A. Motion of particles in shear flows taking into account connected mass. International Journal of Psychosocial Rehabilitation, Pp. 74-77. 2020. https://www.scopus.com/authid/detail.uri?authorId=57210473506 
6. Aybek Arifjanov, Shamshodbek Akmalov, Islombek Akhmedov, Dinislom Atakulov Evaluation of deformation procedure in waterbed of rivers. XII International Scientific Conference on Agricultural Machinery Industry.

7. https://www.scopus.com/authid/detail.uri?authorId=57214102503

8. Akmalov Sh.B., Gerts J. Using Remote Sensing very high resolution data in observation of open drainage system condition in Syrdarya Province. Journal "Irrigation and melioration", No2 (4). TIIAME. Tashkent, 2016. Pp. 26-29

9. Akmalov Sh.B., Blanpain O., Masson E. Study of ecological changes in Syrdarya province by using the Remote Sensing GEOBIA analysis method. Journal "Irrigation and melioration", Vol N02 (8). TIIAME. Tashkent, 2017. Pp.15-19

10. Aybek Arifjanov, Shavkat Kenjabaev, Hans Frede and Tursinoy Apakhodjaeva Ecohydrology and irrigation water management in the fergana valley. "CONMECHYDRO-2020".

11. Aybek M. Arifjanov, Shamshodbek B. Akmalov, Tursunoy U. Apakhodjaeva, Dilmira S. Tojikhodjaeva Comparison of pixel to pixel and object based image analysis with using WORLDVIEW-2 satellite images of Yangiobod village of Syrdarya Province. GISCA-2020.

12. Arifjanov A.M., Ibragimova Z.I., Axmedov I.G'. Analysis Of Natural Field Research In The Assessment Of Processes In The Foothills, The American Journal of Applied sciences. - 2020. - T. 2. - №. 09. - Pp. 293-298.

13. Alsubaie, N.M. (2012). The Potential of Using Worldview-2 Imagery for Shallow Water Depth Mapping. Université de Calgary. Alberta, $85 \mathrm{p}$.

14. Awan, Usman Khalid. "Coupling Hydrological and Irrigation Schedule Models for the Management of Surface and Groundwater Resources in Khorezm, Uzbekistan." Accessed June 2017. 105 p.

15. Conrad, Christopher, Sebastian Fritsch, Julian Zeidler, GerdRücker, and Stefan Dech. "Per-Field Irrigated Crop Classification in Arid Central Asia Using SPOT and ASTER Data." Remote Sensing 2 (4): Pp. 10351056.

16. Dubovyk, O., Menz, G., Conrad, C., Thonfeld, F. \& Khamzina, A. Object-Based Identification of Vegetation Cover Decline in Irrigated Agro-Ecosystems in Uzbekistan. Quaternary International, Hydrological and Ecological Responses to Climatic Change and to Land-use/land-cover changes in Central Asia, Pp. 163-174.

17. Gerts J., Samiev, L. N. Ispol'zovanie distantsionnogo zondirovaniya izobrazheniy s ochtn' vysokim razresheniem pri nablyudenyy za tekhnichesrimi usloviyami otkrytoy drenazhnoy sistemy v Syrdar'inskoy oblasti [Using The Remote Sensing of Very High Resolution Images in Observation of Technical Conditions of Open Drainage System in Syrdarya Province.] Science and World, No 12 (28). Vol. III. Pp. 136-140. (in Russian)

18. Bhattarai, N, Quackenbush, L.J., Calandra, L.J., Teale S. Spectral Analysis of Scotch Pine Infested by Sirex Noctilio. Proceedings of the ASPRS 2011 Annual Conference Milwaukee, Wisconsin, 1- 5 Mai, Pp. 1-5.

19. Blaschke T. Object Based Image Analysis for Remote Sensing. ISPRS Journal of Photogrammetry and Remote Sensing, 65 (1) Pp. 2-16.

20. Dimo Dimov, Fabian Löw, Johannes H. Uhl, Shavkat Kenjabaev, Olena Dubovyk, Mirzahayot Ibrakhimov, Chandrashekhar Biradar, "Framework for agricultural performance assessment based on MODIS multitemporal data” J. Appl. Remote Sens. 13(2), 025501 (2019), Pp. 112-123. https://www.elibrary.ru/item.asp?id=41614776

21. Sh. Akmalov, L. Samiev, D. Atakulov Innovative technologies in evaluation of procedures in riverbed. National Online Conference on Sustainable management of environment \& natural resource through innovation in science and technology, 2020 (SMTST 2020).

22. Flener, C., Wang, Y., Laamanen, L., Kasvi, E., Vesakoski, J.M., Alho, P., 2015. Empirical modeling of spatial 3D flow characteristics using a remote-controlled ADCP system: monitoring a spring flood. Water (Switzerland). Pp. 56-61. https://doi.org/10.3390/w7010217

23. Salmela, J., Kasvi, E., Vaaja, M.T., Kaartinen, H., Kukko, A., Jaakkola, A., Alho, P. Morphological changes and riffle-pool dynamics related to flow in a meandering river channel based on a 5-year monitoring period using close-range remote sensing. Journal Geomorphology. 2020 y. Volume 352. Pp. 6578 . 